\title{
Complications of varicella in a defined central European population
}

\author{
A Jaeggi, R P Zurbruegg, C Aebi
}

\begin{abstract}
Aims-To describe complications of varicella requiring hospitalisation in a defined population (canton of Bern) and to compare the hospitalisation rates for varicella with published data.

Methods-Retrospective analysis of hospital records of patients less than 16 years of age admitted with complications of varicella to the hospitals serving this population (University Children's Hospital of Bern and the Wildermeth Children's Hospital of Biel, Switzerland), and calculation of hospitalisation rates for varicella and its complications based on birth rates and varicella antibody prevalence rates.

Results-From 1986 to 1996, 113 cases (median age, 5.6 years) were identified. Younger siblings were overrepresented (odds ratio $(O R), 1.42 ; 95 \%$ confidence interval (CI), 1.09 to 1.84$)$. Central nervous system (CNS) complications (26 patients; $23 \%$ ) were found predominantly in previously healthy children (relative risk, $7.1 ; 95 \%$ CI, 1.01 to 49.86$)$. Group A $\beta$ haemolytic streptococci were recovered from only one of 35 patients with bacterial complications. The hospitalisation rates for primary varicella $\left(9.2 / 10^{4}\right.$ cases; $95 \%$ CI, 7.4 to $\left.11 / 10^{4}\right)$, skin infections $\left(2.0 / 10^{4}\right.$ cases; $95 \% \mathrm{CI}, 1.2$ to $2.9 / 10^{4}$ ), and pneumonia $\left(0.8 / 10^{4}\right.$ cases; $95 \%$ CI, 0.3 to $\left.1.3 / 10^{4}\right)$ were significantly lower than reported previously. The CNS complication rate $\left(2.2 / 10^{4}\right.$ cases; $95 \% \mathrm{CI}, 1.3$ to $\left.3.1 / 10^{4}\right)$ was among the highest rates reported.

Conclusions-The low hospitalisation rate in comparison with studies from elsewhere indicates that there is a large regional variability in complications associated with varicella. Such data should be taken into consideration when local varicella immunisation strategies are developed. (Arch Dis Child 1998;79:472-477)
\end{abstract}

Keywords: varicella; complications; epidemiology; Streptococcus pyogenes

Hospital, CH-2502

Biel, Switzerland

R P Zurbruegg

Correspondence to:

Dr Aebi.

email: christoph.aebi@insel.ch

Accepted 6 August 1998 most of the morbidity caused by primary cella in children. ${ }^{1}$ Therefore, universal immunisation at the age of $12-18$ months is currently recommended in the USA. ${ }^{2}$ In Europe, routine vaccination against chickenpox has not become standard practice, despite the commercial availability of the varicella vaccine. ${ }^{3}$ In the USA, comprehensive data on complications and costs incurred by varicella contributed to the rationale for implementing universal immunisation ${ }^{4}$; however, similar data from Europe are scant. European cost effectiveness analyses using epidemiological data derived from USA studies ${ }^{6}$ are of limited value for a number of reasons. First, rates of complications of varicella determined by surveying hospital discharge records ${ }^{7-9}$ or primary care institutions ${ }^{9}{ }^{10}$ reflect local admission and consultation policies. Although unlikely to confound estimates on severe complications that uniformly require hospitalisation, consultation and referral policies for minor complications may differ regionally and affect the results of cost-benefit studies. Second, the age specificincidences of primary varicella appear to shift over time, ${ }^{811}$ thereby modifying the clinical manifestations. Third, the rate and severity of varicella zoster virus (VZV) related secondary infections might vary with respect to climate, living conditions, and the virulence of bacterial pathogens.

Our study aimed to generate data on complications of varicella requiring hospitalisation in a defined population in central Europe. The aims were to determine: the rate of hospitalisation of children with complications of primary varicella; the rates of severe complications of varicella; their clinical characteristics among healthy and chronically ill children; and the role of group A $\beta$ haemolytic streptococci (GABHS) in secondary infections.

\section{Methods}

Hospital records of patients less than 16 years of age diagnosed with varicella infections or their complications caused by VZV who were admitted to the University Children's Hospital of Bern or the Wildermeth Children's Hospital of Biel, Switzerland, were reviewed. These institutions were the only paediatric hospitals in the canton of Bern and served a defined population during the study period from 1 January 1986 to 31 December 1996. Patients were identified using the international classification of diseases (ICD), ninth revision, codes 052 (varicella), 053 (Herpes zoster), 053.0 (H zoster with meningitis), 
Table 1 Complications of varicella infection requiring hospitalisation and the position in the family $(n=111)$

\begin{tabular}{llccc}
\hline Position in family & $\begin{array}{l}\text { Median age (years) } \\
\text { (interquartile range) }\end{array}$ & $\begin{array}{l}\text { Observed } \\
(n(\%))\end{array}$ & $\begin{array}{l}\text { Expected } \neq \\
(n(\%))\end{array}$ & OR (95\% CI) \\
\hline Only child & $5.0(1.8,7.7)^{\star}$ & $18(16)$ & $27(24)$ & $0.67(0.39$ to 1.14$)$ \\
Oldest sibling & $6.8(5.6,8.6)$ & $25(23)$ & $36(32)$ & $0.69(0.45$ to 1.08$)$ \\
Younger sibling & $4.1(1.8,7.6)^{\star}$ & $68(61)$ & $48(44)$ & $1.42(1.09$ to 1.84$) \dagger$ \\
Total & $5.6(2.0,7.6)$ & $111(100)$ & $111(100)$ & \\
\hline
\end{tabular}

${ }^{\star} \mathrm{p}=0.497$ (Mann-Whitney U test)

tp $=0.0007$ ( $\chi^{2}$ test $)$.

$\ddagger$ From the population statistics of the canton of Bern.

53.1 ( $H$ zoster with other central nervous system (CNS) complications), and 053.2 ( $H$ zoster with ocular complications). Case definition consisted of historical or physical evidence of primary varicella or $H$ zoster within 14 days of onset of a condition, which required hospitalisation, and to which VZV contributed. Pre-existing illness was defined as any condition requiring continuous medical attention. Immune dysfunction consisted of congenital or acquired immunodeficiency, malignancy, or immunosuppressive treatment within 30 days of admission. The term "complication" was applied to all varicella associated events resulting in hospitalisation. Primary encephalitis was defined as altered level of consciousness and/or focal neurological abnormality, together with an abnormal electroencephalogram and/or cerebrospinal fluid (CSF), white blood cell (WBC) count $>5 \times 10^{6} / 1$. The diagnosis of cerebellar ataxia was accepted if ataxia was present. Disseminated varicella required abnormalities in at least two parenchymal organs. Hepatitis was defined as raised alanine aminotransferase and aspartate aminotransferase values $\geqslant 200 \%$ of the upper limit of the normal range. The diagnosis of Reye syndrome was accepted when fulminant hepatocellular necrosis occurred in a patient with varicella receiving salicylate treatment. Secondary bacterial infection was accepted if a documented (pathogen isolated from infection site and/or bloodstream) or probable (characteristic clinical presentation without recovery of causative organism) bacterial infection was present. Additional evidence was required for the diagnosis of osteomyelitis $\left({ }^{99} \mathrm{mTc}\right.$ bone scan) and pneumonia (abnormal chest radiograph together with raised peripheral WBC count, erythrocyte sedimentation rate, or $\mathrm{C}$ reactive protein). Invasive GABHS infection and streptococcal toxic shock syndrome were diagnosed using the consensus definitions. ${ }^{12}$ Data were analysed by age, sex, country of origin, number and ages of household members, attendance in a day care centre or school, pre-existing illness, aetiology and manifestations of the VZV related complications, duration of hospitalisation, need for intensive care support, and surgical intervention.

\section{STATISTICAL ANALYSIS}

The StatView software package (Abacus Concepts Inc, Berkeley, California, USA) was used. Datasets were compared using the two tailed Student's $t$ test or Mann-Whitney U test, where appropriate. Proportions were compared using contingency tables $\left(\chi^{2}\right.$ test or Fisher's exact test). Confidence intervals (CI) were calculated as described previously. ${ }^{13}$
Population statistics were obtained from the Federal Office of Statistics. The rate of hospitalisations for each $10^{4}$ cases of primary varicella in individuals less than 16 years of age in the canton of Bern was calculated by dividing the number of hospitalisations associated with varicella by the estimated number of varicella cases in the population. This denominator was the mean annual birth cohort $\times$ the study period $(y) \times 0.95 / 10^{4}=11,766 \times 11 \times$ $0.95 / 10^{4}=11.25$. The factor 0.95 corrected for the estimated VZV antibody prevalence of $95 \%$ at the age of 16 years. ${ }^{10}$

\section{Results}

SOCIODEMOGRAPHIC AND CLINICAL CHARACTERISTICS

General population

During the observation period, the total population and the number of individuals under 16 years of age remained stable at $\sim 905000$ and 186000 , respectively. The mean (SD) annual birth rate was 11766 (198). The mean annual migration rate in and out of the canton was $14500(1.6 \%)$. More than $95 \%$ of the population were white, $10.4 \%$ were foreign citizens, and two thirds resided in urban areas. All children had mandatory health care insurance. The average number of children under 16 years of age in each household was 1.8. Comprehensive data on the rate of day care attendance were unavailable.

\section{Study population}

One hundred and thirteen cases (54 girls) residing in the canton of Bern were identified. The number of cases lost because of referral to institutions out of the canton was negligible because the canton of Bern also provides inpatient paediatric services for the neighbouring smaller cantons, and residents of the canton of Bern are required by law to be referred to institutions within the canton. Eighty seven (77\%) and $26(23 \%)$ patients were hospitalised at the study sites in Bern and Biel, respectively. Similar characteristics of these two groups (data not shown) allowed collective analysis of all cases. The median age was 5.6 years (interquartile range, 2.0 to 7.6$)$. Fifty three patients $(47 \%)$ and 14 patients $(12 \%)$ were less than 5 years and 1 year of age, respectively. Patients with foreign citizenship $(n=27 ; 24 \%)$ were overrepresented $(\mathrm{p}=0.0001)$ and were younger than Swiss children (mean (SD) age 4.0 (4.2) $v$ $5.8(3.5)$ years; $p=0.029)$. Eight of 65 patients $(12 \%)$ aged $0-6$ years attended a day care programme.

The numbers and ages of household members were available for 111 cases (98\%). Eighteen patients $(16 \%)$ were the only child in the household, $25(23 \%)$ were the oldest child, and $68(61 \%)$ were a younger child (they had one or more older siblings). Comparison of these proportions with those from the general population of the canton of Bern (table 1) revealed that younger children were significantly overrepresented. Figure 1 shows that younger and only children shared a nearly identical age distribution and that there was a peak at $6-8$ years 


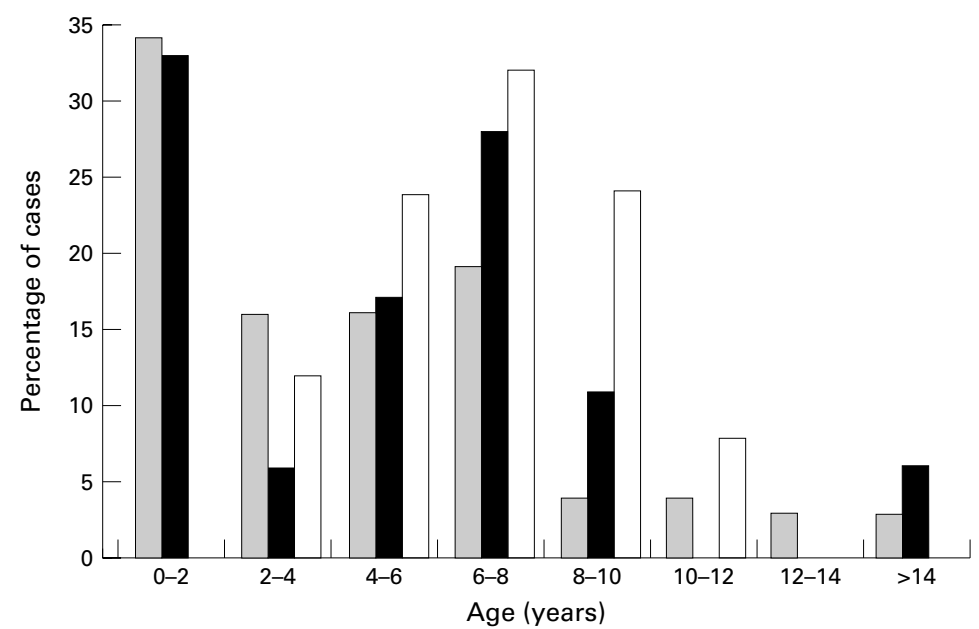

Figure 1 Age specific, relative frequencies of complications of varicella requiring hospitalisation in the canton of Bern, 1986-96. Shaded bars, younger children; Solid bars, only children; Open bars, oldest children in the household.

of age common to only, oldest, and younger children.

\section{Annual frequency and seasonality}

The median annual frequency of cases was 10 (range, 8-13). The highest and lowest frequencies were seen in January (18) and October (two), respectively. A minimum of 14 cases occurred during the trimester from 1 August to 31 October, and a maximum of 42 occurred during the trimester from 1 May to 31 July.

\section{Pre-existing illness}

Pre-existing illness was identified in 25 patients $(22 \%)$. The 12 patients with malignancy (acute lymphatic leukaemia (ALL) in 10, solid tumour in two) received chemotherapy at the time of primary varicella (10) or $H$ zoster (two) infection. Four patients received immunosuppressive treatment for nephrotic syndrome (one), bone marrow transplantation for aplastic anaemia (one), and obstructive lung disease (two). One patient was considered immunocompromised as a result of anorexia nervosa. Five of the eight patients with pre-existing disease of the CNS suffered from neurodevelopmental delay of various aetiologies, two were diagnosed with inborn errors of metabolism, and a seizure disorder was present in one. In these previously ill patients, CNS complications of varicella were rare, while $H$ zoster, severe oral disease, disseminated varicella, and VZV pneumonia occurred more frequently than in healthy children (table 2). Patients with pre-existing illness were older (mean (SD) age $7.6(4.0) v 4.7$ (3.3) years; $p=0.0001$ ), and had a shorter delay from onset of varicella to admission (mean (SD) 2.0 (1.8) v 5.0 (3.3) days; $\mathrm{p}<0.0001)$ than previously well children.

COMPLICATIONS OF VARICELLA

The VZV associated conditions leading to admission and their frequencies among well and previously ill children are listed in table 2. The number of complications exceeded the number of patients because more than one complication was seen in some patients. For the comparison of major groups of complications, such as CNS complications, secondary bacterial infections, and other complications, each case was assigned to one group only (table 3). Three patients with both CNS and bacterial complications were assigned to the former group because their bacterial infections did not warrant hospitalisation.

\section{CNS complications}

Parenchymal CNS disease associated with primary varicella and $H$ zoster was diagnosed in 25 patients and one patient, respectively. Of these, 21 had cerebellar ataxia with (five) or without (16) other neurological signs. Patients with CNS disease were significantly older, less often febrile on admission, and presented later in the course of varicella than patients with other complications (table 3). Seizures in association

Table 2 Number of children (\%) with complications of varicella infection requiring hospitalisation

\begin{tabular}{|c|c|c|c|c|}
\hline Complication * & $\begin{array}{l}\text { Total } \\
(n=113)\end{array}$ & $\begin{array}{l}\text { Well children } \\
(n=88)\end{array}$ & $\begin{array}{l}\text { Ill children } \\
(n=25)\end{array}$ & $R R(95 \% C I)$ \\
\hline Neurological & $26(23)$ & $25(28)$ & $1(4)$ & $7.10(1.01$ to 49.86$)$ \\
\hline Cerebellar ataxia & $16(14)$ & $15(17)$ & $1(4)$ & $4.26(0.59$ to 30.71$)$ \\
\hline Primary encephalitis & $10(9)$ & $10(11)$ & 0 & \\
\hline Febrile seizure & $9(8)$ & $9(10)$ & 0 & \\
\hline Herpes zoster & $9(8)$ & $6(7)$ & $3(12)$ & $0.57(0.15$ to 2.11$)$ \\
\hline Stomatitis & $8(7)$ & $4(5)$ & $4(16)$ & $0.28(0.08$ to 1.06$)$ \\
\hline Enteritis & $7(6)$ & $7(8)$ & 0 & \\
\hline Disseminated varicella & $6(5)$ & $3(3)$ & $3(12)$ & $0.28(0.06$ to 1.32$)$ \\
\hline Varicella pneumonia & $6(5)$ & $1(1)$ & $5(20)$ & $0.06(0.01$ to 0.46$)$ \\
\hline Hepatitis & 4 & 1 & 3 & \\
\hline Neonatal varicella & 2 & 2 & 0 & \\
\hline Obstructive bronchitis & 2 & 2 & 0 & \\
\hline Reye syndrome & 1 & 1 & 0 & \\
\hline Pancreatitis & 1 & 1 & 0 & \\
\hline Arthritis & 1 & 1 & 0 & \\
\hline Idiopathic thrombocytopaenic purpura & 1 & 1 & 0 & \\
\hline Miscellaneous & 22 & 9 & $13 \dagger$ & \\
\hline Secondary bacterial infection & $35(31)$ & $30(34)$ & $5(20)$ & $1.70(0.74$ to 3.93$)$ \\
\hline Impetigo/cellulitis/abscess & $23(20)$ & $22(25)$ & $1(4)$ & $6.25(0.89$ to 44.11$)$ \\
\hline Pneumonia & $4(4)$ & $3(3)$ & $1(4)$ & \\
\hline Osteomyelitis & 2 & 2 & 0 & \\
\hline Septicaemia & 1 & 0 & 1 & \\
\hline Other $\ddagger$ & 6 & 4 & 2 & \\
\hline
\end{tabular}

* Some children had more than one complication. †Hospitalised for varicella complicating pre-existing illness.

$\ddagger$ Otitis media in four patients, sinusitis in two. 
Table 3 Clinical charactistics of varicella zoster virus associated complications

\begin{tabular}{|c|c|c|c|c|c|}
\hline \multirow[b]{2}{*}{ Characteristic } & \multicolumn{4}{|l|}{ Complication } & \multirow[b]{2}{*}{ p value } \\
\hline & CNS $(n=26)$ & Bacterial $(n=32)$ & Other $(n=55)$ & Total $(n=113)$ & \\
\hline Median age in years (interquartile range) & $6.6(4.5,7.7)$ & $2.8(1.2,6.3)^{\star}$ & $5.6(2.2,7.6)$ & $5.6(2.0,7.6)$ & $0.49^{\star}$ \\
\hline Number $(\%)$ of female patients & $10(38)$ & $14 \quad(44)$ & $30 \quad(55)$ & $54(48)$ & \\
\hline Number $(\%)$ with pre-existing illness & $1(4) \dagger$ & $5(16)$ & $19 \quad(35)$ & $25 \quad(22)$ & $0.01 \dagger$ \\
\hline Interval from onset of varicella to onset of complication (days) (SD) & $5.2(2.7) \ddagger$ & $2.4(1.7)$ & $2.3(2.5)$ & $3.0(2.6)$ & $<0.0001 \ddagger$ \\
\hline Interval from onset of varicella to admission (days) (SD) & $7.4(3.1) \ddagger$ & $3.9(2.3)$ & $3.2(2.9)$ & $4.3(3.2)$ & $<0.0001 \ddagger$ \\
\hline Maximum temperature $\left({ }^{\circ} \mathrm{C}\right)(\mathrm{SD})$ & $37.4(1.0)$ & $39.1(1.1) \ddagger$ & $38.7(1.2)$ & $38.5(1.3)$ & $0.001 \ddagger$ \\
\hline Number $(\%)$ with maximum temperature $>38.0^{\circ} \mathrm{C}$ & $4(15) \dagger$ & $27(84) \dagger$ & $38 \quad(69)$ & $69 \quad(61)$ & $<0.01 \dagger$ \\
\hline Mean (SD) peripheral WBC count $\left(\times 10^{9} / 1\right)$ & $8.5(4.5)$ & $11.1(5.0) \ddagger$ & $8.5(4.8)$ & $9.2(4.9)$ & $0.02 \ddagger$ \\
\hline Number $(\%)$ with immature WBC count $>15 \%$ & $0+\quad-$ & 15 (47) & 11 (20) & $26 \quad(23)$ & $0.002 \dagger$ \\
\hline Number (\%) with intensive care unit admission & $2(8)$ & 1 (3) & $3(5)$ & $6 \quad(5)$ & \\
\hline Mean (SD) duration of hospitalisation (days) & $9.0(4.9)$ & $7.9(6.0)$ & $5.7(3.9)$ & $7.1(5.0)$ & \\
\hline
\end{tabular}

^Mann-Whitney U test $v$ study population.

$+\chi^{2}$ test $v$ study population.

$\ddagger$ Unpaired Student’s $t$ test $v$ study population.

Table 4 Hospitalisation rates for primary varicella and its most common complications

\begin{tabular}{|c|c|c|c|c|c|c|c|}
\hline \multirow[b]{2}{*}{ Authors } & \multirow[b]{2}{*}{$\begin{array}{l}\text { Year } \\
\text { (ref) }\end{array}$} & \multirow[b]{2}{*}{ Country } & \multirow{2}{*}{$\begin{array}{l}\text { Age } \\
\text { group } \\
\text { (years) }\end{array}$} & \multicolumn{4}{|c|}{ Number of hospitalisations $110^{4}$ cases } \\
\hline & & & & $\begin{array}{l}\text { All hospitalisations } \\
(n=104)\end{array}$ & $\begin{array}{l}\text { Skin infection } \\
(n=23)\end{array}$ & $\begin{array}{l}\text { Pneumonia } \\
(n=9)\end{array}$ & $\begin{array}{l}\text { CNS complication } \\
(n=25)\end{array}$ \\
\hline Present study & 1998 & Switzerland & $0-16$ & $9.2(7.4 \text { to } 11.0)^{\star}$ & $2.0(1.2 \text { to } 2.9)^{\star}$ & $0.8(0.3 \text { to } 1.3)^{\star}$ & $2.2(1.3 \text { to } 3.1)^{\star}$ \\
\hline Yawn et al & $1997^{14}$ & USA & $0-12$ & 55 & & & 11 \\
\hline Peterson et al & $1996^{7}$ & USA & $0-15$ & 18 & $6 \dagger$ & $1.3+$ & $1.4 \dagger$ \\
\hline Fairley et al & $1996^{10}$ & Scotland & $0-14$ & $29 \dagger$ & & & \\
\hline Choo et al & $1995^{15}$ & USA & $0-14$ & $51 \dagger$ & $20 \dagger$ & $4.9 \dagger$ & $2.4 \dagger$ \\
\hline Huse $e t$ al & $1994^{5}$ & USA & $0-15$ & 16 & & & \\
\hline Varughese & $1988^{16}$ & Canada & $0-15$ & 51 & & & \\
\hline Guess et al & $1986^{9}$ & USA & $0-14$ & 9 & 2.6 & 1.3 & 0.9 \\
\hline Preblud et al & $1984^{17}$ & USA & $0-14$ & 17 & & & 0.17 \\
\hline
\end{tabular}

${ }^{\star} 95 \%$ confidence interval.

†Extrapolated from raw data provided in the study.

with VZV occurred in 13 patients (12\%), and were classified as febrile seizures in nine, seizures in association with pre-existing CNS disease in three, and seizure as a manifestation of primary encephalitis in one.

\section{Secondary bacterial infections}

Secondary bacterial infections occurred in 35 patients $(31 \%)$, and in 32 of these patients the bacterial complication was the reason for hospital admission. Superficial infections, such as impetigo, cellulitis, and skin abscess, were found in 23 patients. Of seven patients with invasive bacterial infections, four had pneumonia (with bacteraemia as a result of Acinetobacter sp. in one patient with ALL), two had osteomyelitis (no organisms isolated), and one had septic shock caused by Escherichia coli. GABHS was isolated in a single case of cellulitis, and Staphylococcus aureus was isolated from superficial infection sites in eight patients.

Complications of varicella in infants

Five of 14 infants were admitted for secondary bacterial infections of the skin or mucous membranes. Febrile seizures occurred in three infants, neonatal varicella in two, and pneumonia, gastroenteritis, $H$ zoster, and disseminated varicella in one each.

\section{Feeding difficulties associated with VZV related} illnesses

In 22 patients (19\%), feedings difficulties were noted as a reason for hospital admission, and in 12 of these patients $(11 \%)$, inadequate oral intake was the main reason for admission.
Feeding difficulties were attributed to severe mucosal involvement in eight patients, enteritis in seven, recurrent vomiting in five, and refusal to feed in two.

Prophylaxis, treatment, and outcome

Three of 12 patients undergoing chemotherapy for malignancy developed chickenpox, despite having received varicella immunoglobulin upon VZV exposure. All but one of these cancer patients were given intravenous aciclovir and intravenous immunoglobulin for treatment of varicella. Overall, 30 patients $(24 \%), 17$ $(15 \%), 26(23 \%)$, and $41(36 \%)$ were treated with intravenous aciclovir, intravenous immunoglobulins, intravenous antibiotics, and oral antibiotics, respectively. Twelve of 35 patients with bacterial infections received oral antibiotics at the time of admission. The average (SD) duration of hospitalisation was 7.1 (5.0) days. None of the patients required surgical intervention. Six patients $(5 \%)$ were admitted temporarily to the intensive care unit. All patients survived and major sequelae at hospital discharge were not recorded.

EPIDEMIOLOGY OF COMPLICATIONS OF VARICELLA Because the two study sites served a defined paediatric population, the observed number of cases provided the numerator for calculating age specific annual incidences of varicella associated hospitalisations. These were as follows: age $<1$ year, $11.8 / 10^{5}$ population; $1-4$ years, $8.7 / 10^{5} ; 4-9$ years, $8.7 / 10^{5} ; 9-16$ years, $1.9 / 10^{5}$; $0-16$ years, $6.0 / 10^{5}$. Table 4 lists the overall hospitalisation rate for each $10^{4}$ cases of 
primary varicella and the rates of the three most important complications. Nine cases of $H$ zoster, including single cases of pneumonia and CNS complication, respectively, were excluded. Previously published figures are listed for comparison (table 4).

\section{Discussion}

Evaluating the need for routine immunisation against varicella requires the availability of accurate estimates on both the rate and severity of complications of chickenpox and the cost effectiveness of different immunisation strategies in a given population. Our study provides epidemiological and clinical data on complications of varicella in children in a defined area of central Europe. Some results differ considerably from data obtained in North America and the UK (table 4) and warrant consideration when developing local immunisation strategies.

CLINICAL CHARACTERISTICS

The spectrum of complications, age, and sex distributions, and the proportion of immunocompromised hosts among children hospitalised for varicella were consistent with previous reports. ${ }^{78-20}$ As demonstrated for bacterial complications, ${ }^{21}$ younger children in the household were significantly over represented, indicating their increased risk of being hospitalised for VZV related events (table 1). This observation was not explained by the lower age of younger siblings because only children, who were underrepresented compared with their presence in the general population, had a nearly identical age distribution (fig 1). This finding suggests that secondary household cases of varicella not only suffer from more extensive cutaneous involvement than primary cases, ${ }^{22}$ but carry a greater risk of hospital admission for complications.

CNS disease and secondary bacterial infections were the most frequent complications (tables 2 and 3 ). As previously reported, ${ }^{18} 19$ CNS complications occurred at an older age, were less likely to be present in patients with pre-existing illness, and occurred later in the course of varicella than other complications (tables 2 and 3). Secondary bacterial infections were mostly confined to the skin and subcutaneous tissue, occurred at a younger age, and were associated with significantly higher body temperature and peripheral WBC counts on admission than other complications (tables 2 and 3). The mean interval from onset of varicella to admission for bacterial superinfection was substantially shorter than reported in a recent study (mean (SD) interval 3.9 (2.3) v 5.7 (3.2) days). ${ }^{21}$ GABHS, the predominant pathogen responsible for bacterial complications of varicella in recent studies, ${ }^{721}$ was isolated only once, and there were no documented invasive GABHS infections, such as necrotising fasciitis or streptococcal toxic shock syndrome. The true number of superficial GABHS infections might have been higher because one third of patients received antimicrobial treatment before cultures were obtained. However, the absence of documented invasive infections is remarkable, considering the recent emergence of invasive GABHS in the area surveyed. ${ }^{23}$ In North America, the emergence of invasive GABHS infections since the mid- $1980 \mathrm{~s}^{24-26}$ was parallelled by an increasing frequency of such infections complicating varicella. ${ }^{21} 27{ }^{28}$ Possible explanations for this discrepancy are: (1) the cold climate, with streptococcal skin colonisation being less frequent and mainly occurring in summer, while varicella peaks in winter ${ }^{29}{ }^{30} ;(2)$ the low frequency of day care attendance; (3) favourable living conditions; and (4) the short interval from onset of varicella to admission. Bacterial complications were significantly less likely to be found among patients with pre-existing illness, ${ }^{7}$ possibly reflecting the caretakers' heightened awareness of the risks of varicella in these patients. There was only one case of Reye syndrome during the 11 year study period. Our study and earlier reports surveying the $1980 \mathrm{~s}^{17}{ }^{18}$ document that this entity has virtually disappeared as a complication of varicella, while being diagnosed in 17 of 96 hospitalised patients (20\%) with complicated varicella reported by Fleisher in $1981 .{ }^{19}$

RATE OF HOSPITALISATIONS FOR COMPLICATIONS OF VARICELLA

Estimates of the annual rate of primary varicella in the population surveyed served as the denominator for calculating the rate of complications. Age specific antibody prevalence data from the UK indicated that the VZV antibody prevalence at the age of 15 years was greater than $90 \%{ }^{10}$ Thus, the annual rate of primary varicella was estimated at $95 \%$ of the annual live birth rate. The hospitalisation rate of $9.2 / 10^{4}$ cases of primary varicella proved significantly lower than most figures reported previously (table 4)..$^{7_{11}^{14-1631}}$ Even if we assume a $20 \%$ loss of cases owing to incorrect ICD codes (130 cases instead of 104), and a VZV antibody prevalence of $80 \%$ rather than $95 \%,{ }^{10}$ the hospitalisation rate $\left(13.7 / 10^{4}\right.$ cases; $95 \% \mathrm{CI}, 11.4$ to $16.0 / 10^{4}$ ) would still differ significantly from these published data. The accuracy of the only American study ${ }^{9}$ reporting a similarly low hospitalisation rate of $9 / 10^{4}$ has been questioned ${ }^{17}$ by referring to a study surveying the same population and time period which, by using a different notification system, identified nearly twice as many hospitalisations for varicella (Amler RW, 17th immunization conference, Atlanta, USA, 1982). ${ }^{32}$ The low overall hospitalisation rate in our population was a result, at least in part, of the low rate of skin infections. These were either less frequent or required less frequent hospitalisations. It is intriguing to speculate that this observation might be related to the low recovery rate of GABHS. Other possible explanations for the low hospitalisation rate are the low frequency of day care attendance, the small average number of children in each household, and the unrestricted availability of health care resources.

In contrast, the rate of 2.2 CNS complications $/ 10^{4}$ cases of varicella was among the highest rates reported ${ }^{71531}$ and validates 
the overall accuracy of our case catchment. The only substantially higher rate, $11 / 10^{4}$ cases of varicella reported by Yawn, ${ }^{14}$ was based on one observed case and might be inaccurate.

In conclusion, complications of varicella requiring hospitalisation in children were two to five times less frequent than reported elsewhere, preferentially affected younger siblings in the family, and were rarely associated with secondary infection caused by GABHS. Our results indicate that, for a given population, local studies are needed for assessing the community burden of varicella, estimating cost effectiveness of the varicella vaccine, and establishing local immunisation strategies.

1 Gershon AA. Viral vaccines of the future. Pediatr Clin North Am 1990;37:689-707.

2 American Academy of Pediatrics. The 1997 red book. Elk Grove Village, Illinois: American Academy of Pediatrics, 1997.

3 Ross LF, Lantos JD. Immunization against chickenpox. BMF 1995;310:2-3.

4 Lieu TA, Cochi SL, Black SB, et al. Cost-effectiveness of a routine varicella vaccination program for US children. FAMA 1994;271:375-81.

5 Huse DM, Meissner HC, Lacey MJ, Oster G. Childhood vaccination against chickenpox: an analysis of benefits and costs. F Pediatr 1994;124:869-74.

6 Beutels P, Clara R, Tormans G, Van Doorslaer E, Van Damme P. Costs and benefits of routine varicella vaccination in German children. F Infect Dis 1996; 174(suppl 3):S335-41.

7 Peterson CL, Mascola L, Chao SM, et al. Children hospitalized for varicella - a prevaccine review. 7 Pediatr 1996;129: 529-36.

8 Preblud SR. Age-specific risks of varicella complications. Pediatrics 1981;68:14-17.

9 Guess HA, Broughton DD, Melton LJ, Kurland LT. Population-based studies of varicella complications. Pediatrics 1986:7(suppl):723-7.

10 Fairley CK, Miller E. Varicella-zoster virus epidemiology-a changing scene ? F Infect Dis 1996;174(suppl 3):S314-19.

11 Miller E, Vurdien J, Farrington P. Shift in the age of chickenpox. Lancet 1993;341:308-9.

12 The Working Group on Severe Streptococcal Infections. Defining the group A streptococcal toxic shock syndrome: Defining the group A streptococcal toxic shock syndrome: ration 1 .
13 Morris JA, Gardner MJ. Calculating confidence intervals for relative risks, odds ratios, and standardized ratios and rates. In: Morris MJ, Altman DG, eds. Statistics with

14 Yawn BP, Yawn RA, Lydick E Community impact of childYawn BP, Yawn RA, Lydick E. Community impact of ch

5 Choo PW, Donahue JG, Manson JE, Platt R. The epidemilogy of varicella and its complications. F Infect Dis 1995;172:706-12.

16 Varughese PV. Chickenpox in Canada, 1924-87. Can Med Assoc f 1988;138:133-4.

17 Preblud SR. Varicella: complications and costs. Pediatrics 1986;78:728-35.

18 Jackson MA, Burry VF, Olson LC. Complications of varicella requiring hospitalization in previously healthy children. Pediatr Infect Dis ₹ 1992;11:441-5.

19 Fleisher G, Henry W, McSorley M, Arbeter A, Plotkin S. Life-threatening complications of varicella. Am $\mathcal{F}$ Dis Child 1981;135:896-9.

20 Manfredi R, Chiodi F, Titone L, et al. Chickenpox complications among immunocompetent hospitalized children in cations among immunocompetent hosp

21 Aebi C, Ahmed A, Ramilo O. Bacterial complications of primary varicella in children. Clin Infect Dis 1996;23:698-705

22 Ross AH. Modification of chicken pox in family contacts by administration of gamma globulin. $N$ Engl $f \mathrm{Med}$ 1962;267:369-76.

23 Gamba MA, Martinelli M, Schaad HJ, et al. Familial transmission of a serious disease-producing group A streptococcus clone: case report and review. Clin Infect Dis 1997;24:1118-21.

24 Givner LB, Abramson JS, Wasilauskas B. Apparent increase in the incidence of invasive group A beta-hemolytic

25 Rathore MH, Barton LI Kaplan EL Suppurative group A $\beta$-hemolytic streptococcal infections in children. Pediatrics 1992;89:743-6.

26 Stevens DL. Streptococcal toxic-shock syndrome: spectrum of disease, pathogenesis, and new concepts of treatment. Emerging Infectious Diseases 1995;1:69-78.

27 Doctor A, Harper MB, Fleisher GR. Group A betahemolytic streptococcal bacteremia: historical overview, changing incidence, and recent association with varicella. Pediatrics 1995;96:428-33.

28 Vugia DJ, Peterson CL, Meyers HB, et al. Invasive group A streptococcal infections in children with varicella in southern California. Pediatr Infect Dis f 1996;15:146-50.

29 Ferrieri P, Dajani AS, Wannamaker LW. Natural history of impetigo. I. Site sequence of acquisition and familial patterns of spread of cutaneous streptococci. 7 Clin Invest 1972;51:2851-62.

30 Taplin D, Lansdell L, Allen AM. Prevalence of streptococcal pyoderma in relation to climate and hygiene. Lancet 1973; 501-3.

31 Preblud SR, Orenstein WA, Barth KJ. Varicella: clinical manifestations, epidemiology and health impact in children. Pediatr Infect Dis f 1984;3:505-9. 